\title{
Turkish prospective kindergarten teachers' conceptions concerning some selected atmospheric events
}

\author{
Engin Baysen", Fatma Baysen \\ Ataturk Education Faculty, Near East University, Nicosia, North Cyprus
}

\section{Email address:}

bengin71@gmail.com (E. Baysen)

\section{To cite this article:}

Engin Baysen, Fatma Baysen. Turkish Prospective Kindergarten Teachers' Conceptions Concerning some Selected Atmospheric Events. International Journal of Elementary Education. Vol. 2, No. 5, 2013, pp. 32-37. doi: 10.11648/j.ijeedu.20130205.11

\begin{abstract}
Prospective kindergarten teachers $(n=144)$ participated in the present study including answering a questionnaire about conceptions concerning some selected events that occur in the atmosphere: wind, cloud, rain, hail, snow, thunder and lightning. Analysis included participants explanations (including participants' teaching), and drawings (with notes) about the concept itself and occurrence of the event represented by the concept. All the participants in the present study were found to have had at least one misconception concerning the concepts or formation of the events which are good candidates for transmitting to the next generation; they are still found to be bound by stereotype phrases and overgeneralized use of clichés; lack knowledge and may have dual views concerning selected atmospheric events. Not in all contexts but they can use their conceptions consistently. They were found to have a tendency to use analogies and models while explaining events. Participants' answers were categorized thus: affected; contaminated by teaching/ schooling and formed by worldview features of the participants. Implications for teaching are discussed.
\end{abstract}

Keywords: Prospective Teachers, Conceptions, Atmospheric Events

\section{Introduction}

Conception learning and teaching are crucial to science lessons, but are challenging too. Numerous studies showed that people, ranging from children to adults, experience difficulties in learning scientifically accepted conceptions, and misconceptions do occur while learning conceptions concerning science lessons. Research showed that many misconceptions or naive conceptions are inevitable, robust and can resist any attempt to change (e.g. [1]; [2]), even to teaching programs specialized in eliminating them [3].

Atmospheric events attract pupils' attention from childhood. Children try to interpret them with conceptions of weather schematized long before the beginning of their formal education. Kindergarten school curriculum expects teachers to teach about the events that occur in the atmosphere [4]. On the other hand research showed that young children have difficulty in understanding conservation of liquid - a prerequisite for learning water cycle - [5] making teaching issue more difficult. Adding [6] found that only at the age of five can pupils start developing the concept of 'evaporation' which can only become scientific at the age of fourteen years of age. This does not automatically mean to disclude the subject from the program but to take care not to cause the formation of misconceptions and to facilitate the construction of the related knowledge by implementing core issues that will be used in interpreting many phenomena. To enable kindergarten teachers overcome these problems, they should be fully acquainted with the relevant conceptions especially those related with water cycle. This is particularly important because even prospective kindergarten teachers' conceptions concerning atmospheric events can be different from those of the scientists. On the other hand [7] states the need for learning the water cycle as it facilitates learning another more comprehensive approach to the environment: system thinking, which accordingly will contribute in enhancing attitudes to the environment.

\subsection{Research Findings}

Many research studies dealt with people thinking concerning the events occur in the earth's atmosphere and especially water cycle - emphasizing evaporation and condensation. Many misconceptions concerning the issue can be cited ([5], [8]: pp.41, [9], [10], [11], [12], [13], [14], [6], [15] [16], [17], [18], [19], [20], [21], [22], [23], [24], [25]). 


\subsection{Significance of the Study}

Three main reasons motivated the generation of the present study. Firstly, to the author's knowledge, earlier research concerning conceptions of the atmospheric phenomenon dealt with cloud and rain in search for pupils' conceptions concerning evaporation and condensation. Only few have been conducted on wind, thunder, lightning and precipitation types: hail and snow. Secondly research found that pupils' thinking can include the same mechanism for scientific phenomena. For example, explain the formation of both rain and the thunder by the "collision of the clouds". Consistency in using a conception is considered as an important property [26, 27], whether scientific or naive, which enables understanding of how deep-rooted and applicable a conception is. So participant responses were also analyzed to decide to be categorized as consistent or inconsistent. Present study has the benefit to add, by revealing thinking concerning related phenomena and interrelationships between these concluding in coherency discussions. Lastly there is not much research study found concerning teacher candidates' conceptions including their reasoning concerning atmospheric events. So present study had a more comprehensive and in-depth approach to the phenomena concerning atmospheric events by including prospective kindergarten teachers, other related phenomena and by including the discussions concerning pupils' consistencies related with the conceptions in question.

\subsection{Purpose}

Accordingly the aim of the study can be summarized by the following three problem statements,

1. Which (mis)conceptions do prospective kindergarten teachers have concerning atmospheric events?

a. Wind b. Cloud c. Rain d. Hail e. Snow f. Thunder and g. Lightning (lightning1 and lightning2)

2. Do the participants of the present study use their conceptions concerning the atmospheric events consistently?

3. How can the participants' misconceptions be categorized due to their reasoning (probable causes) ?

\section{Method}

\subsection{The Participants}

Kindergarten teacher education lasts four years in Turkish programmes of the universities and is one of the departments take part in education faculties. Those finishing the programme can become teachers at kindergarten schools including 36-72 months. Participants $(n=144)$ of the present study were in their first semester of their fourth year. At the time of the application of the questioner all the participants of the present study were already taught "kindergarten science teaching" lesson (in their first semester of third year) and were found successful.
Kindergarten science teaching lesson is one of the two lessons to include science subjects but only the ways of teaching of science not aiming to teach science subjects. The other lesson taking part in the programme: "human anatomy and physiology" not designed to have any relation with atmospheric events. Participation in the research was voluntary. Only five of the participants were boys; so, gender was not considered a variable. Turkish was the mother tongue of all the participants. Participants were from all over parts of Turkey where different weather conditions can be experienced. All the participants of the present study confirmed that they have experienced all the weather events in concern of this study at least in one day of their lives.

\subsection{The Procedure}

Essay type questions relating to events: wind, cloud, rain, hail, snow, thunder and lightning were included in the questionnaire. To distinguish between the lightning formed by the passing of electrons between two clouds, and between clouds and the earth, questions for each were asked separately as lightning1 and lightning2 respectively to gauge participants' conceptions. Participants were asked to illustrate their concepts or the events through drawings (proposed by [28] as a data collection method), along with explanatory notes if they consider their drawings are not adequately self-explanatory. Providing multiple forms of data ([29]: p.175) from each participant regarding a concept is thought to on one hand increase the reliability of the research. And on the other hand increase the reliability of the researcher categorizations regarding participants' consistencies. Participants were given one lesson time and enough blank papers to answer. Also, it was made clear to them that in answering the questions they were free to relate or compare one concept with other concept/s in question.

\subsection{Method of Analysis}

Present study was descriptive in nature. Data analysis was carried out to identify concepts and patterns in participants' responses. Data gathered from sample of thirty participants' responses were analyzed first separately by the researcher and a colleague. Any conflict aroused solved before final decisions for categorization. Following data analysis were made by the two together. The explanations, together with drawings and notes, given by the participants for the concepts of wind, cloud formation, rain, hail, snow, thunder, lightning1 and lightning2, were analyzed. Most participants added to their explanations the ways of teaching the concepts and those explanations also were analyzed. Some conceptions, though mentioned by fewer participants, are considered worth analyzing because they are either interesting (candidate to further detailed investigations) or useful in supporting main interpretations or findings. Participants using same reasoning in at least two concepts were accepted showing consistency regarding 
the issue. Lastly, comprehensive analysis was carried out including all answers for categorizing possible sources, reasoning of conceptions.

\section{Results}

\subsection{Conceptions}

All the participants in the present study were found to have had at least one misconception concerning wind, cloud, rain, hail, snow, thunder or lightning. Following are the explanations to summarize participants' conceptions concerning wind, clouds, rain, hail, snow, thunder, lightning1 and lightning2.

\subsubsection{Wind}

Participants stated that wind forms because of pressure differences but none of them explained the process in detail. Wind was seen by most participants as a cooling agent. The most stated feature is that it occurs during cold days. Although not stated by many participants, two interesting but mutually contradictory explanations offered by some are as follows: "wind starts the weather events including raining" and "wind prevents raining". The answer which needs further probing for more detailed data is that the wind occurs because the earth revolves. Participants who gave these explanations might have done so because of the fact that moving things can cause blowing (also discussed in [8]: pp.71 where "clouds move to make wind").

\subsubsection{Clouds}

Bar (as cited in [17]) found that some children cited kettle as an example of the source for the formation of clouds but participants of the present study used kettle (and teapot) only to discuss the rain model and they thought that only a large body of water (ocean, sea and lake) can lead to the formation of clouds. Adding all participants' drawings included mountain and a sea as seen in most books consistent with the findings of [25]. Evaporated water goes up to the clouds and is enclosed there. The clouds are thought to be solid pockets of water (containers). What is kept inside by clouds is water, not vapor; there is no need for phase change. Some preferred to draw an analogy between the clouds and cotton wool or sponge. The art lessons in schools where cotton and sponge are used to represent clouds can be the possible source for this conception.

Some participants were found to be afraid of the gathering of black clouds as "they are messenger of storms". It is thought that, just like misconceptions, fear also can be transmitted to next generations and thus impede learning. Clouds are formed by smoke coming from the chimneys. This answer also reminds the view that everything happening is caused by human act. For example, students think that mainly people cause environmental changes or problems [30]. A variety of explanations concerning visibilities and colors of clouds and water vapor are found which need probing. For example clouds are always there, but seen only occasionally (visible when they become black) when they are excessively filled with water (and it is going to rain). The following is an interesting answers which related the cloud formation with the seasons and there is no mention of such relation in earlier research: "evaporation occurs in summer (when the sun shines) and it rains in winter".

\subsubsection{Rain}

The analogies drawn for clouds by some participants to some kind of solid things, like cotton, sponge (rain comes from the clouds) and container-like things (clouds leave their water to the world) are thought to be consistent with participants' views that rain is caused by two clouds colliding (hitting) or compressing each other. Another type of explanation given by about $1 / 5$ of the participants was that the encounter of water vapor with a layer of cold air results in the formation of rain. This explanation ignores the need for clouds for rain, thus: clouds and rain are unrelated in their thinking. This thinking appears to have stemmed from or supported by the rain model-- boiling water in a container to show the formation of water droplets on container cover (cold layer) -- frequently used in science lessons. Some participants of the present study used both views in their explanations for rain. Both the views impede comprehension of the water cycle from scientists' viewpoint. Some participants think that clouds come down when it rains.

\subsubsection{Hail}

The most common explanation goes thus: "it starts hailing when water encounters a layer of cold air". Two other explanations referred to phase changes are as follows: "snow becomes hail" and "hail is the mixture of rain and snow". Remembering that hail is also made of water, some participants stated that "it starts hailing when rain increases in intensity". Another very interesting answer, though given by only one participant, is that "some objects in the sky decompose for hailing". This seems to imply an analogy between hail and meteors. It starts hailing when air cools and when air rises (used air instead of water vapor). So it can interpreted that most participants believe that hail stones start their voyage from cloud (or from a layer of cold air) as water (rain) and change their state to hail when they pass through a layer of cold air.

\subsubsection{Snow}

Most participants explained the relationship between rain, hail and snow by phase changes. Some participants used the analogy of cotton for snow, and again air was used instead of water vapor. Snow, like hail, starts its voyage from cloud (or from a layer of cold air) as water (rain), which changes its state to snow or hail and then to snow when it passes through a layer of cold or hot air respectively.

\subsubsection{Thunder}

For the formation of thunder most of the participants 
stated that there should be a collision between clouds (and inversely charged). Participants explained the ways of teaching the formation of thunder by examples that can cause misconceptions (e.g. clapping hands). Some participants used the word 'rub' instead of 'collision'. One answer which supports that clouds are container-like things is that they have air enclosed in them and that when this air comes out of the clouds, thunder occurs. Thunders occur in winter.

\subsubsection{Lightning1}

Like thunder, for the formation of lightning1, most of the participants stated that there should be a collision between clouds (and inversely charged) and that lightning occurs in winter.

\subsubsection{Lightning2}

Like thunder and lightning1, for the formation of lightning2, most of the participants stated that there should be a collision (more rigorous than for the formation of lightning1) between clouds. Other two interesting answers are those that the lightning2 strikes and damage only trees and hunter guns and kills only hunter dogs are thought to be the effect of media. Adding most of the students drew the sun to show the need for evaporation. Two of the participant's answer showed the need for the sun in their statements as well. Some participants showed how the sun and clouds fight for their dominancy in sky in their drawings and notes. If the sun wins, rain or lightning will not occur. Some participants did not show water-vapor in their drawings, but most of them did show it (vertically along the earth and clouds) as wave-like features and others as vertical arrows heading to the clouds. However, these drawings cannot be utilized for discussing the visibility of water-vapor. On the contrary, other explanations and drawings, added in the answer sheets by the participants for their future teachings (rain model), showed that at least some participants think that water-vapor is visible.

\subsection{Consistency in Conceptions}

Participants were found to use some of their concepts consistently. Same thinking were depicted, explained and applied in different events. They drew and stated large bodies of water, such as sea or lake, to take part in each precipitation types. They stated consistently that water vapor is visible. They stated that evaporation of water causes the formation of both cloud and rain (need not distinguish between the two). They used the conceptions of collision of clouds and charged clouds as the causes for hail, thunder and lightning. They explained the relationship between rain, hail and snow by phase changes using "layer of cold (or cooler) air". They stated that wind, cloud, rain, hail, thunder, lightning1 and lightning2 form in winter season or cold weather.

\subsection{Reasoning (Probable Causes)}

Possible reasoning in answering can be grouped into two categories. The first category includes misconceptions contaminated by schooling [31]: contaminated by teacher or book, affected by figures or drawings in books (stated as a problem by [32] also), and by language. The second category includes misconceptions formed by worldview features of the participants: overgeneralization [33], animism and teleology thinking which were discussed by many for example [34].

i) Misconceptions affected/ contaminated by teaching/ schooling:

- Contaminated by teaching. Contaminations are thought to be occurred because of some misconceptions pupils held, while naturally including naive conceptions but also those that are taught. For example the concept "collision of inversely charged clouds" both include "collision" as a naive thinking but also "inversely charged clouds" as a thinking created at class.

- $\quad$ Affected by figures or drawings in the books. Many students draw a sea or lake and a mountain as found in most science books ignoring small bodies of water.

- Affected by language. For example, in mother tongue the word "fall" is used to refer to the occurrence of lightning2.

ii) Misconceptions formed by worldview features of the participants:

- Overgeneralization of conceptions. For example, "for the formation of sound two things should hit each other").

- Animism. For example, the sun and the clouds fight for dominance in the sky because they are living creatures and they want to do so, or "snow waits in the sky until the weather is cold enough for it to appear".

- Teleology. Explanations attributing end purpose. For example: "clouds are formed whenever it's going to rain")

\subsection{Summary}

Most of the responses for the formation of wind, clouds, rain and thunder showed that prospective kindergarten teachers have misconceptions about atmospheric events which are similar to those found in earlier research. But some other still not found in related research as well. For example some of those related (multilayered) complex phase changes and some which are culture depended. Pupils' neglected the phase changes for the formation of the clouds and rain. This was not the case in the present study for the formation of hail and snow and participants consistently used the phase change phenomenon in their explanations. Although most participants of the present study did try to use some mechanistic explanations, they are still found to be bound by stereotype phrases (e.g. heated air rises) and overgeneralized use of clichés. They lack knowledge and may have dual views concerning selected atmospheric events. Participants of the present study were found to have a tendency to use analogies and models while explaining events. For example, they 
considered clouds and snow are like cotton, or clouds store water (like containers do). And, clouds hit each other like two stones or two cars for the formation of rain, thunder and lightning. Participants proposed to use rain model in teaching. These analogies are considered candidates in supporting or creating misconceptions for children. Participants of the present study tend to relate events of excessive concern to each other by drawing cause and effect relationships. For example lightning causes rain; hailing starts when intensity of rain increases; water freezes in cold layer to form hail and then hail is heated in cool layer to decompose to snow; when intensity of lightning1 increases, lightning2 occurs.

Generation of pupils' misconceptions was categorized as affected/ contaminated by teaching/ schooling. They were contaminated by teaching, affected by figures or drawings in the books and the language used at school. On the other hand they are also thought to be generated due to pupils' worldview features: The tendency to overgeneralize their conceptions to non related contexts. Adding to the tendency to overgeneralize, animistic and teleology reasoning are the other two.

\section{Conclusions}

Turkish prospective kindergarten teachers have misconceptions regarding atmospheric events which are thought to be good candidates to be transmitted to new generations. Participants were found to use some of their concepts consistently. Generation of pupils' misconceptions were affected/ contaminated by teaching/ schooling or are formed by worldview features of the participants.

\section{Implications}

It is important to use relevant concepts, analogies, drawings and models, as proposed by [14] and multimodal approach [35] for explaining atmospheric events in classes by teachers and in science books. Although relating natural events to one another is important in understanding systems, it is even more important to first teach prospective kindergarten teachers all supplementary phenomena and systems concerning atmospheric events. There seems to be a need for motivating pupils to depend on their observations, experiences and in and out of class discussions designed exclusively enhancing conceptions concerning atmospheric events.

\section{References}

[1] J.Clement. The use of analogies \& anchoring intuitions to remediate misconceptionsin mechanics. Paper presented at the Annual Meeting of American Educational Research Association, Washington, DC. 1987.

[2] K. Longden, P. Black, and J. Solomon. Children's interpretation of dissolving. International Journal of Science Education, 13(1), 59-68, 1991.
[3] J., P. Smith III, A. A, diSessa and J. Roschelle. Misconceptions Reconceived: A constructivist Analysis of Knowledge in Transition. Journal of the Learning Sciences, 3 (2), 115-163, 1994.

[4] [4] F. Sahin. Teaching Science and Activity Examples in Kindergarten. Istanbul: YAPA, 1981.

[5] D. Inbody. Children's understanding of natural phenomena. Science Education, 47(3), 270-278, 1963.

[6] V. Bar and I. Galili. Stages of child ren's views about evaporation. International Journal of Science Education, 16 (2), 157-174, 1994.

[7] O.Ben-Zvi Assaraf and N. Orion. Four case studies, six years later: developing system thinking skills in junior high school and sustaining them over time. Journal of Research in Science Teaching, 47 (10), 1253-1280, 2010.

[8] J. Piaget. The child's conception of physical causality (Chapter II and Chapter III). Translated by Marjoire Gabain. New Jersey: Littlefield, Adams \& Co. Totowa, 1969.

[9] G. I. Za'rour. Interpretation of natural phenomena by Lebanese school children. Science Education, 60 (2), 277-287, 1976.

[10] R., J. Osborne and M.,M. Cosgrove. Children's conceptions of the changes of state of water. Journal of Research in Science Teaching, 20 (9), 825-838, 1983.

[11] V. Bar. Children's views about the water cycle. Science Education, 73 (4), 481-500,1989.

[12] M., C. Dibar Ure and D. Colinvaux. Developing adults' views on the phenomenon of change of physical state in water. International Journal of Science Education, 11(2), 153-160, 1989.

[13] T. Russel, W. Harlen and D. Watt. Children's ideas about evaporation. International Journal of Science Education, 11(5), 566-576, 1989.

[14] V. Bar and A. S. Travis. Children's views concerning phase changes. Journal of Research in Science Teaching, 28 (4), 363-382, 1991.

[15] T. Russel, D. Bell, K. Longden and L. Mc Guivan. Rocks, soil and weather. Primary SPACE Project Research Report. Liverpool: Liverpool University Press, 1993.

[16] P. Johnson. Children's understanding of changes of state involving the gas state.Part 2: Evaporation and condensation below boiling point. International Journal of Science Education, 20, 695-709, 1998.

[17] Bar as cited in R. Driver, A. Squires, P. Rushworth and V. Wood-Robinson. Making sense of secondary science: research into children's ideas (pp.101-102). New York: Routledge, 1999.

[18] A.A. Taiwo, H. Ray, M.J. Motswiri, and R. Masene. Perceptions of the water cycle among primary school children in Botswana. International Journal of Science Education, 21(4), 413-429, 1999.

[19] L. Henriques. Children's misconceptions about weather : A review of the literature. Paper presented at The Annual Meeting of the National Association of Research in Science Teaching, New Orleans, LA., 2000. 
[20] R. Tytler, S. Peterson and V. Prain. Picturing evaporation: Learning science literacy through a particle representation. Teaching Science, 52 (1), 12-17, 2006.

[21] E. Baysen, B.K. Temiz, F. Baysen and R. Yagbasan. Secondary School Students' Misconceptions Concerning Some Selected Events Occuring in the Atmosphere (Vol.2, pp.1979-1992). Paper presented in XII. Institute of Educational Sciences Congress: Ankara. Gazi Institude of Educational Sciences, 2004.

[22] B. Costu and A. Ayas. Evaporation in different liquids: secondary students' conceptions. Research in science and Technological Education, 23 (1), 75-97, 2005.

[23] S. Alk1s. A study on the primary school students perceptions of precipitation concept. (Unpublished doctoral dissertation). Uludag University, Bursa, Turkey, 2006.

[24] M. Varelas, C.C. Pappas and A. Rife. Exploring the role of intertextuality in conceptconstruction: Urban second graders make sense of evaporation, boiling and condensation. Journal of Research in Science Teaching. 43 (7), 637-666, 2006.

[25] D. P. Shepardson, B.Wee, M. Priddy, L. Schellenberger and J. Harbor. Water transformation and storage in the mountains and at coast: Midwest students' disconnected conceptions of the hydrologic cycle. International Journal of Science Education, 31(11), 1447-1471, 2009.

[26] E. Engel Clough and R. Driver. A study of consistency in the use of students' conceptual frameworks across different task contexts. Science Education, 70 (4), 473-496, 1986.

[27] D. Palmer. How consistently do students use their alternative frameworks? Research in Science Education, 23 (1), 228-235, 1993.
[28] J. E. Dove, L.A, Everett, and P. F. W. Preece. Exploring a hydrological concept through children's drawings. International Journal of Science Education, 21(5), 485-497, 1999.

[29] J.W. Creswell. Research Design: Qualitative, quantitative and mixed methods approaches. 3rd edition. USA: Sage Publications Inc, 2009.

[30] J. Hillcoat, K. Forge, J. Fien and E. Baker. I think it's really great that someone is listening to us: young people and the environment. Environmental Education Research, 1(2), 159-171, 1995.

[31] A.B. Champagne and L.E. Klopfer. Naive Knowledge \& Science Learning. Paperpresented at the Annual Meeting of the American Association of Physics Teachers, New York, NY, 1983.

[32] R. Tytler. A comparison of year 1 and 6 students' conceptions of evaporation and condensation: dimensions of conceptual progression. International Journal of Science Teaching, 22 (5), 447-467, 2000.

[33] J.K. Mohapatra. Induced in incorrect generalizations leading to misconceptions- an exploratory investigations about the laws of reflection of light. Journal of Research in Science Teaching, 25 (9), 777-784, 1988.

[34] M. Lemmer, T.N. Lemmer and J.J. A. Smith. South African students' views of the universe. International Journal of Science Education, 25(5), 563-582, 2003.

[35] C. M'arquez, M. Izquierdo, and M. Espinet. Multimodal science teachers' discourse in modeling the water cycle. Science Education, 90, 202-226, 2006. 